\title{
Papers
}

Explorations into Children's Literature

\section{Storytelling and Affect in Sonya Hartnett's The Children of the King (2012)}

\section{Rose Miller}

Melbourne writer Sonya Hartnett frequently explores the ways in which a sense of place impacts on the development of identity. In her memoir Life in Ten Houses (2012), Hartnett maps each of her novels to her place of habitation at the time of writing, describing the relationship between each place and herself and the subsequent impact of this dialectic on the creative process. This reciprocal relationship between narrative and lived experience is examined in Hartnett's novel The Children of the King (2012). Using perspectives on temporality from phenomenology and cultural memory and incorporating ideas of place from human and cultural geography, this article proposes that Hartnett uses the device of embedded narrative to examine the affective qualities of storytelling and place on the subject. This juxtaposition invites the reader to consider the fluid notions of identity inspired by embodied oral storytelling along with the perceptual opportunities afforded by the physical, sensorial world. Hartnett encourages the reader to critically assess the reliability of narrative, narrator, and the process of subjective judgement that occurs when responding to story. This recalls Linda Hutcheon's (1989) work on historiographic metafiction, which, as she describes, has the effect of demarginalising the literary 'through confrontation with the historical' (p. 108). Metafictive historiographic novels, as Robyn McCallum (1999) articulates: 'foreground the discursive and textual conventions of history writing, usually by physically incorporating and representing historical texts and discourses in ways that destabilise the relation between fiction, history and reality' (p. 230). In The Children of the King this destabilisation is achieved through Hartnett's double plot structure which calls attention to the constructed and affective elements of historical and fictional narratives and by the employment of the gothic mode within a realist frame. 
The embedded narrative as utilised in The Children of the King reveals the ways in which discourses of power influence the life of the individual subject at a variety of levels; at the micro level in terms of family and peer relationships and at the macro level in terms of sociopolitical, historical, and ideological discourses. The Children of the King begins in London in 1940. Twelve-year-old Cecily and fourteen-year-old Jeremy Lockwood are playing hideand-seek with their father. Wealthy and protected from the fighting through Mr Lockwood's vital but nameless career, possibly in the War Office, the family lives in a suburb of London where Cecily's 'entire world was hiding in darkness, but not because it was playing a child's game' (Harnett 2012, p. 5). Hartnett draws attention to the distinction between private and public evacuation. In wartime, the intervention of the state in public evacuation and the enforcement of parental authority with regard to private evacuation led to the displacement of children. In Hartnett's novel, Mrs Lockwood evacuates her children to the relative safety of the north of England to stay with their Uncle Peregrine in Heron Hall. The children's uncle is also protected from fighting due to a disability. The complexities represented by the divisions of social class are reflected in the behaviour and emotions of both adult and child characters. After travelling first class, the Lockwood family alights at a small rural station where a private car awaits them. However, the public evacuees have to go the community hall for selection by local families. The Lockwood children persuade their reluctant mother that it is her duty to select an evacuee but it is Cecily who chooses. Through Cecily's treatment of May the consequences of the misuse of social privilege are demonstrated at the level of the peer relationship. This power play is subsequently challenged through the narrative's exposure of Cecily's social ineptitude and snobbery in contrast to May's intelligence, maturity, and sensitivity. In wartime, pre-war social inequalities persisted. As May remarks: 'only ordinary people will get squished by bombs. All the important people will be safe' (p. 158). May's mother makes parachutes for the war effort whereas Cecily's mother uses wealth to retreat from it. May's father, a teacher and soldier, has recently died fighting in France which in consequence makes May vulnerable. What is described by Cecily as kindness to strangers is selfish charity motivated by the perceived benefits to the giver. Cecily's growth in the novel is dependent on her realisation that friendship on equal terms builds resilience and that wielding power over others can be self-defeating. War is interrogated by Hartnett as a historicised and territorialised trauma that has consequences for the development of subjectivity. 
The traumatic experience of displacement caused by war-time evacuation is followed by the time shift experience achieved through storytelling of placement in the Wars of the Roses. The deployment of a double temporal frame provides a context for enabling Hartnett's child protagonists to mature and to take up strengthened subject positions. In addition, the children become more critically aware of the consequences of political ideologies, decision making, and historical events. They do this by recognising that such events are characterised by particular patterns of human activity which are motivated by power and repeated through time and place. Power structures can be located and repeated within a variety of spatial and temporal dimensions. Michel Foucault (1980) defines power as war whether in times of conflict or peace and emphasises its repressive nature. The idea of a relationship between place and power is supported by Foucault's assertion that the tactics and strategies of power operate through territories and domains that constitute 'a sort of geopolitics' (p. 77). Here I utilise an understanding of place derived from human geography and defined by Tim Cresswell (2004) as a 'meaningful location' (p. 7) or 'space invested with meaning in the context of power' (p. 12). The reader is positioned as if on the outer rim of concentric circles in which spin two narratives which are historically framed: the first being the overall narrative of the evacuation of children from London during World War Two and the second embedded narrative set in fifteenth-century England in the final stage of the Wars of the Roses and which is used by the child characters to make sense of their current, traumatic displacement. This structure invites readers to compare these narratives with contemporary issues and provides a template through which the meanings of their own experience can be explored.

Story, and its affective qualities, can combine with a sense of place to create meaning for young subjects during times of trauma. The analysis which follows examines how gothic tropes participate in the affective influence of place using one exemplar from the text. Jane Suzanne Carroll (2011) has used the term 'the lapsed topos' to collectively describe representations of ruins, caves, and graves in fantasy literature (p. 133). Utilising the idea of 'topos' and applying this to the gothic, I will examine the ways in which the ruin is employed by Hartnett as a metafictive device. Characterised by an indeterminate fluidity this trope enables the displaced female protagonists to begin to heal and re-orient their lives by combining the affective qualities of place with those of story, resulting in their Entwicklungsroman or journey of growth. The concluding section focuses on how the older male protagonist, Jeremy, channels feelings of frustration and resistance into a circular quest 
narrative, travelling between country and city to achieve the transition from childhood to maturity. This rite-of-passage journey or Bildungsroman is generated by the interpretation of historical grand narrative via a more localised experience of story and the power of affect. As well as functioning as a metafictive device to intensify affect, gothic tropes also provide concrete expression to abstract processes. They provide what Anna Jackson, Karen Coats and Roderick McGillis (2009) have described as useful metaphors for the physical and psychological transitions that young characters undergo not just within the family but in the wider social and cultural context (p. 8). Hartnett's work tends to subvert some of the assumptions associated with gothic tropes, such as re-locating the lost bush child to modern, suburban landscapes. The landscape as a construct is described by Carroll (2011) as: 'at once geographic and historical, natural and cultural, experienced and represented' (p. 2). Each landscape comprises unique 'topological features' which distinguishes it from others (p. 2). Just as physical environments vary, so do imaginary, literary landscapes. In The Children of the King history is represented within Hartnett's characteristically gothic mode but is displaced to an English landscape during World War Two. Consequently, the narrative incorporates tropes of nineteenth-century English gothic, such as an ancient crumbling castle, ghosts, a male villain, bleak moorland, and a rambling manor house. In addition is the suggestion that war itself has gothic potentialities through its unbidden and uncanny irruption into the homely or daily life, making the familiar seem strange and leaving the lives it touches irrevocably haunted by its associated traumas.

Hartnett combines the affective qualities of place with those of the gothic to encourage the reader to connect past with present in order to question contemporary experience. Peregrine describes the castle ruins discovered by May as 'a castle of no name', at least five hundred years old (p. 58). Known locally as 'Snow Castle', the marble structure evokes the white rose of York. Peregrine recognises the children's need for a story but warns: 'I cannot vouch for its absolute truth, but it certainly is history' (p. 61). History is therefore contextualised as part fabrication. Peregrine uses simile and exaggerated language to play to the curiosity children often have for all things ghoulish by stating that the story is 'as hard as winter' and 'unfit for childish ears' (p. 60). They would wake up 'screaming in the night' (p. 62). This seals their interest. May confesses to Cecily that she has discovered two boys living in the ruin. Sequentially, this is prior to Peregrine's story, which challenges reader assumption that the boys are simply imaginary constructs inspired by the tale. Thus, May's experience of haunting has already begun with the phenomenal experience of place. 
The affective qualities of place afforded by the 'ruin' topos of Snow Castle can be located in the physical world of the overarching narrative. However, this does not exclude its imaginative potential. The past, claims Hutcheon (1989), can only be uncovered 'through its traces' (p. 119). Before going further, I would like to refer to the concept of the trace from cultural geography. Jon Anderson (2010) distinguishes between the material traces that are left in places such as buildings, statues etc. and non-material traces which are the emotional spaces, languages, or virtual spaces left by trace-makers (p. 10). Anderson claims: 'By understanding place as an ongoing composition of traces it facilitates the interrogation of these traces and how they come to confer cultural meanings to geographical sites' [emphasis in original] (p. 11). Snow Castle is at once a material and non-material trace. Its liminality, as described in the text, is a form of haunting representing both the accessibility and the inaccessibility of history:

It had had wings and ramparts and thin windows from which to shoot arrows, internal courtyards, banquet rooms, hidden doors, secret passages. It had had a chapel and, in its bowels, a dungeon. It had housed sculptures and paintings, tapestries and cushions, carpets and carvings, its fortressed heart had been clad in gilt, silver, glass, gold, damask, ivory, ermine... (p. 69)

This reference to the bowels and heart of a building transforms Snow Castle into an embodied metaphor of life which is at the same time an image of death, for in its reversion to decay and entropy the castle also wears coats of 'festering slime' and the collapsed walls leave 'only ragged stumps, knee-high, overgrown, to show where rooms had been' (pp. 6970). The instability of the castle's boundaries foreshadows the permeability of other boundaries such as that between the normal and paranormal, the present and past, fact and imagination. Buildings then, or material traces become connected with non-material traces and take on ghost-like qualities. If, like Simon Hay (2011) we define the ghost as a 'presentabsence, ... visible and yet invisible' then the concept of place must accommodate this duality (p. 4). As the narrator in The Children of the King testifies: 'Although most of Snow Castle's walls and all of its roof were missing, their very absence told of things that had been ... And all these seemed here rather more than they weren't here...[emphasis in original] (p. 160). Snow Castle represents the ways in which place can inspire the imagination towards story and can complete those gaps and absences that are suggested by the story's framework. The 'ruin' topos can affect mood and this leads to events which are in turn enacted upon place. This relationship is affirmed by Arno Meteling (2010) who describes how the Gothic tale establishes: 'an almost corporeal connection between the protagonists and the buildings 
they are situated in' (p. 188). The gothic ruin is always already a spectre. It assists the ghost story as a means of narrating trauma or what has been unnarratable. Hay (2011) comments on the associations with the past that the ghost story carries: 'To be concerned with ghost stories is to be concerned with suffering, with historical catastrophe and the problems of remembering and mourning it' (p. 4). Thus, Snow Castle is place and no-place, where the uncertainties and imaginings of history dwell and where the unresolved traumas of history are endlessly played out. As a borderland it becomes an environment in which the girls perform and develop their sense of identity.

The Children of the King provides examples of the performative possibilities which can be generated by story and mediated by memory. Enactment enables subjects to take ownership of narrative. For example, imitating Peregrine's story which describes how Elizabeth of York attempted to retain the younger Prince in a place of sanctuary despite demands that he attend his brother's coronation, the girls return to Snow Castle to play an imaginative game of sanctuary. May performs the role of the Duke and Cecily the role of Queen. However, both girls are overcome by the affective qualities of the ruin. May declares: 'It's strange. Most of the castle has gone, but - it feels like it's here, doesn't it?' (p.160). The phenomenal experience of place works with story to pervade the imagination, offering a gothic infusion of melancholy and potentiality. Cecily and May initially believe that the two boys they encounter at Snow Castle are evacuees in hiding from their foster homes. Only towards the end of Peregrine's story does May perceive the royal identities of the homeless boys who are dressed as if for 'a pantomime' (p. 82). This is, ironically, because of the games of war that the boys play (p. 192). The elder of the brothers admits that he is "nothing but a frightened boy' suggesting that soldiering is also a performance which disguises true fears and vulnerabilities (p. 167).

Memory can be described as a form of haunting caused by the juxtaposition of temporal and spatial zones. Collective memories, as psychologists David Manier and William Hirst (2010) define: 'are representations of the past in the minds of members of a community that contribute to the community's sense of identity' (p. 253). Cultural memories are intergenerational and are maintained by material objects such as texts, monuments, and events. Memories of war and inherited remembrance contribute to the construction of national as well as individual identity. Political discourses continue to affect the ways that nations build alliances and respond to crises. Both narratives within The Children of the King explore the 
construction of History and present grand narratives as being composed of sureties and slippages, collective and individual memory, re-imaginings, propaganda, and myth.

Just as the physical properties of place can produce 'affect', so too can the power of embodied story. Whereas place interacts more freely with the subject's sensorial perceptions, the teller uses the tale manipulatively in order to convey an ideological and moral perspective. Words, non-verbal communication, tone of voice, and actions are skilfully employed to influence listeners. Hartnett draws attention to the fact that the formal education of the children is disrupted by the war but is replaced by Peregrine's storytelling, encouraging the reader to make comparisons. Wanting the children to perceive historical relevance, Peregrine begins: 'You might think it's a story from a dark age. But the world is at war as we sit here, tearing itself up like a pack of wolves: maybe, hundreds of years from now, this era we live in will likewise appear a dark and ignorant age' (p. 99). Peregrine describes how the Duke lost his father and brother at the age of nine and that his life in a feudal society during the Wars of the Roses had been shaped by bloodshed. He had learned that 'might crushes right"' (p. 101). In not naming the Duke as Richard III and indicating that beyond his life he would have 'many names', this historical figure becomes symbolic of the pursuit of power (p. 101). Peregrine uses the technique of repetition to fix the theme in the children's memories: "Power [italics in original]. I want you to remember this word. I want you to say it to yourself, feel its weight in your hand. Look into its dark depths every time this story takes a turn' (p. 102). He adds that once the quest for power has begun, 'the destination always seems to shift ever further away' indicating a territorial or colonial element to power (p. 106). This is suggestive of an ever receding frontier located in space as well as time. By using embedded narrative to expose these techniques, Hartnett is able to demonstrate both the power of embodied, interactive storytelling and the constructed nature of history.

Peregrine employs gothic conventions to achieve gothic affect, insisting on the curtains being drawn in the middle of the day commenting enticingly 'It's a story for the dark' (p. 185). In order to link the everyday with the gothic, he comments that what has been frightening about the story so far is seeing what power can do. Cecily feels that it is silly to be scared about something that happened hundreds of years ago but Peregrine insists that the story is relevant to the present because otherwise the current King and Queen would not be on the throne, adding 'Don't think history doesn't touch you, Cecily. The past lives everywhere'(p. 186). Peregrine is being didactic here because the obtuse Cecily is not experiencing the appropriate 
'affect'. When considering the role of the storyteller it is helpful to consider Maria Nikolajeva's (2010) concept of 'aetonormativity' or the inevitable power position of the adult over the child which can be deliberate or unconscious (p. 203). Here, the storyteller has an agenda or moral message that he is relying on the story to transmit. The room chosen for the storytelling is cosy and safe and everyone is fed and relaxed, enabling optimal receptivity to the stimulus provided by narrative. During pauses, Peregrine encourages questions and often challenges the children's assumptions. As he describes how the Duke became King 'on a tide of lies and disloyalty', Cecily affirms that 'Nothing good is going to happen to him. Bad people aren't happy' (p. 189). Peregrine uses this comment to refer to power and the price that it can exact from individuals. To encourage engagement and feelings of empathy for the imprisoned Princes he also uses personalisation such as 'What do you do when it's raining or you're ill and you can't go outdoors?' (p. 192). In this way, the children develop temporal as well as spatial intersubjectivity, perceiving historical others as sensing beings and in this scenario put themselves in the place of the Princes. Peregrine also encourages the children to visualise the events of the story, asking the most imaginative and sensitive child: 'Can't you see it, May?' (p. 193). As May visualises, she begins to see not only the imagined scene of the story but also to 'see' in terms of understanding, realising at last the significance of the boys in Snow Castle. Cecily remains immune to Peregrine's efforts, so he piles on vivid adjectives to his description of the captivity of the doomed Princes as a 'suffocating, lonely, living death, trapped in a beautiful tomb' (p. 194). After describing how the Princes were carried away in the night, Cecily is still waiting for a happy ending but Peregrine darkly insists 'Nothing was left living but a stray beetle' (p. 196). What is required of Cecily is an acceptance that not all stories end happily and that stories based on the pursuit of power and centred on real events rarely do.

Through story and the phenomenal experience of place, each of Hartnett's young protagonists make the transition from a position of denial to a historicised sense of place which enables them to accept and cope with their fears. After the story's uncompromising ending, Cecily feels as if her skin is made of glass and is filled with trepidation about the world in which she will grow up. She has been anxious about her father's safety during the London bombing and seeks reassurance. Nevertheless, this awareness is also part of her growth. At what point, Hartnett is suggesting, do adults cease to ignore the gothic in the everyday that is continually perceived by children? How can these anxieties which are rooted in the material world yet displaced by culture be acknowledged and processed? Choosing the right time to tell children 
particular stories and selecting the appropriate performative mode and methodology is a skill that Horst Kornberger (2008) insists can make a difference to the ways in which children experience affect and create meaning: 'by telling the right tale at the right time we maximise its healing potential. If we don't place our stories squarely in time, we easily tread the same ground, over and over, slip or even fall' (p. 12). Kornberger is positive about the effectiveness of embedded narrative, adding: 'stories reveal themselves as co-creators of cultures, shaping the destiny of whole nations as well as of our individual lives' (p. 12). Affective processes, when used with careful consideration, in the most appropriate time and place, can help young subjects to make important adjustments and act as guides for the development of resilience and agency. Through collective cultural memory, stories will frequently be inherited by future generations but Hartnett demonstrates how even historical grand narratives can be interpreted, mediated, and made new to suit audience and purpose. Stories do not need to be fresh to be interesting but even when selected carefully, listeners need to be ready to hear them. The final part of the analysis will examine the ways in which the process of affect experienced through place and through storytelling ultimately builds resilience and agency in all of the children.

The female protagonists come to growth through belief, empathy, and friendship and the main catalyst for these changes are the possibilities afforded by the liminal topos of the gothic ruin. Cecily, yearning for her own absent father, has been humbled by the way in which May has coped with bereavement. Cecily is ashamed of her selfish behaviour and acknowledges her faults. The girls have become friends, accepted the reality of death as a part of life and the interrelatedness of past, present, and future. This understanding has led to resilience. Despite displacement they have developed empathy and the motivation to help the ghost Princes who are temporally displaced. Just as the girls make the symbolic threshold crossing over a stream to reach Snow Castle, the Princes eventually demonstrate agency and make the ultimate crossing to what Edward describes as 'the place of the fathers' (p. 169). Sophie Anne Edwards (2010) explains how this type of passage represents non-Cartesian connections between sites, time, subjects, and awareness and is related to culture, story, and the preservation of both (p. 246). Furthermore, in keeping the presence of the boys a secret the girls exercise independence and a subversive form of power over their adult carers. Carroll (2011) describes how the ruin 'not only connects the past to the present but hints at 'potential futures' (p. 158). As Peregrine concludes the story, the girls hear and understand the connection between the embedded narrative and Snow Castle: 
Everything I've told you of this story so far has been fact - you can read it in any history book, see paintings of the Duke, the Queen, the Tudor in galleries, see artefacts from their lives in museums. But Snow Castle takes us into the realms of wishes and imaginings ... Snow Castle stands not in the real world, but in the land of what-could-be' (pp. 226-227)

Carroll reminds us that ruins are 'simultaneously sites of desire and part of the geography of despair'. Potential spaces of colonisation, 'their boundaries are vulnerable and open to the rites of power' (p. 158). Hartnett, while acknowledging this potential vulnerability, demonstrates through the speculative metaphor of Snow Castle that the girls are not colonisers but co-conspirators, eager to work positively with the liminal other in order to achieve new possibilities for peace, and this presents the reader with a choice for their own time and place.

The contention that time can only be made sense of through subjectivity is asserted by phenomenologist Maurice Merleau-Ponty (1945), who, having distinguished between Cartesian (or historical and linear) time and natural time, proposes that the order imposed by historical time is somehow artificial and that time 'is a dimension of being' (p. 438). Events recur through time. For example, the tendency of human cultures to repeat wars against other nations persists despite the apparent freedom of future generations to choose peaceful ways of living. Choice, of course, can be limited by various factors, including cultural norms. As Roberta Seelinger Trites (2000) contends, assuming responsibility involves balancing individual power with: 'recognition of the social forces that require [young subjects] to modify their behaviours' (p. 5). Nevertheless, the recognition and understanding of power structures can assist subjects as agents to influence and resist them. As Foucault (1980) asserts, power only exists in action and, in common with ideas of identity, is continually being re-made. The understanding of power gained by the child protagonists in The Children of the King is enhanced by the emotion or 'affect' that the intimate process of storytelling involves, ultimately leading to resilience despite the threat of trauma posed by war. Jeremy, the Lockwood's eldest child, also challenges the assumption that children are without power. Resentful from the outset that he must leave his father in London to seek the protection of Heron Hall, Jeremy is desperate to help with the war effort: 'Trapped out here in the country he was a wild beast chained, a dog of war muzzled, a worthy warrior lamed' (p. 94). When Heloise criticises the King and Queen for staying in London when Buckingham Palace is bombed, Jeremy retorts: 'They're proving they are no better than everyone else' and is 
ashamed of his mother for wanting to be safe when others are dying 'so you can be kept that way' (p. 176). Heloise has sought safety for her children and there is an intertextual parallel with the fifteenth-century decision of Elizabeth of York to find sanctuary for the two Princes in a place of religious protection. In the embedded narrative, Peregrine describes how Richard III's strategy of detaining Edward V en route to London resulted in a shift in the balance of power. Jeremy at this point believes that children have no power and this makes him angry. Peregrine embellishes the story to emphasise and make real the fear of the Princes: 'Every footstep, every turn of a key, would have made their blood run cold' (p. 194) and by using affect to promote empathy encourages Jeremy to identify with the plight of Edward and Richard. This is so successful that the following morning Jeremy reclaims power over his life and runs away to London.

Towards the end of the novel, the child, with new-found authority, replaces the adult as storyteller and another embedded narrative begins. When Jeremy returns to Heron Hall three days later he has also completed his Bildungsroman. The landscape of the narrative shifts to a London evening in the Blitz where the grey dust of the bombing touches everything and tastes of 'all the centuries it had taken to build the city' (p. 246). Unlike the liminal positioning of the gently crumbling Snow Castle, the bombed-out ruins of the London buildings are stark testaments to how daily life is configured. Indeed, it is the occasional suburban road which is so far untouched by destruction that is perceived by the subject as unreal and liminal. Jeremy is cast in the role of a young hero seeking maturity and independence: 'he thought of all the boys who had gone before him, the ones who endured fearsome trails on desert plains, in frail canoes, on horseback ... trials of pain, confusion, skills, wisdom, strength and, most of all, of courage' (p. 247). Here, the adventure story is relocated in the war-torn city before a bombing raid. Instead of perceiving the wildness within nature as a frontier combatant or place to colonise, Jeremy is faced with the consequences of the wildness within humanity; the primal drive that fuels the desire for narcissistic power. He craves to spend the night outside: 'away from somewhere safe' [emphasis in original] ( $\mathrm{p}$. 248). The only living heir to the wealth of Heron Hall runs towards the working-class area, physically and symbolically closing the gaps of social division. His intervention is embodied and emotional as he works frantically to free a family trapped in a rapidly flooding cellar. Yet even now, he is affected by the story of the Princes: 'I saw, in my mind, all these children behind doors ... I could not let wrongness and cruelty and greed and - power - win' (p. 255). Jeremy's quest then is not for 'power over' others but for 'power to'; a distinction drawn by 
feminist theorist Marilyn French (1985) which usefully summarises the difference between empowerment and the desire to control. Jeremy strives for a 'real' role in a community, which includes taking positive action to empower those who need help. Psychologist Jan Horwath (2001) uses the term 'social capital' to summarise the need for connectedness as a pre-requisite for resilience and defines this as a 'web of relationships based on norms of trust, reciprocity and mutual identification' (p. 178). Thus, Jeremy makes a different or nonpatriarchal choice. His realisation is that it is impossible for historical accounts to consider Richard III without being haunted by the fate of the Princes. He decides: 'The Duke was a king, but it was those boys who ruled him, and have ruled him for five hundred years, and will always rule him. I thought, You think a child has no power, but you're wrong' [emphasis in original] (p. 256). The cellar door opens and he saves a family of seven. He realises that although his contribution to the total war effort was small, it was also 'a mighty thing' and mightier than war itself (p. 257). The story of the Princes has developed Jeremy's understanding of the ways in which power operates. He is aware not just of political ideology, military strategy, and the ways in which history is constructed but also of his own potential contribution to society; of the need for community involvement and transparency in order to challenge those who wield power negatively against the powerless.

\section{Conclusions}

The Children of the King explores power relations at the level of the individual, the family, and peer relationships and at the level of social class, political strategy, and ideology. Hartnett interrogates the ways in which positions of wealth and privilege are misused, utilising feudal and modern timeframes in order to demonstrate repetitions in human behaviour patterns, particularly within patriarchy and associated discourses. Hartnett challenges the iconic image of the vulnerable evacuee waiting on the station platform for the adults to decide her/his fate. Children are revealed as potentially secretive, subversive, conspiratorial, and disobedient to the will of adults. The displaced children in The Children of the King rebel against isolation and instead create their own web of social capital in which to build their resilience. They develop connectedness with each other, with story, with place and time, and with community and reveal empowering qualities such as empathy, wisdom, independence, honesty, and courage. 'Power to' is shown to be not just internal and individual but external, political, and social. The text represents children as capable of more than is assumed by adults. After Jeremy runs away to London the narrator comments that his 
mother 'never recovered from the realisation that children are wilful people; she never trusted them again' (p. 212).

The Princes as ghosts in the narrative represent the unresolved moral issues of history that haunt public consciousness, the collective unconscious and the private conscience. Although the past in The Children of the King appears to be in a different country, this country is at the same time part of world history; part of what everyone inherits. Hartnett employs gothic tropes to affirm the affective consequences of inherited cultural memories and the persistence of the past in the present. The gothic serves to reassert the power of mythical time over linear time by offering uncanny experiences which prompt this experience of the interconnection of different temporal zones. This metafictive gothic affect helps to articulate the subjective perception and experience of time where memories can be vividly recalled and imaginings projected into the future; where days can be lost in an instant and some moments last forever. Hay asserts: 'The ghost story, like the historical novel'... questions 'how the present inherits that past, how we get from there to here' (p. 13). The idea of time as a journey links the temporal with the spatial. The lost ghosts of the Princes inhabit the borderland between the living and the dead; the known and the unknowable. They mark the present as distinct from the past and at the same time the persistence of the past into the present. The historical periods and settings described in the novel share the centrality of traumatic transition and depict the structure of empire as a series of repetitions of Europe's bloody transition into modernity.

In juxtaposing two different historical timeframes, Hartnett makes the process of historymaking transparent for the reader drawing attention to the connections between different periods of history, as well as the differences. Exposing the myths and uncertainties surrounding the character and actions of Richard III provides an opportunity to assess the various ways in which historical narratives comprise a mixture of conjecture, chance, factual evidence, and opinion. This can be at the level of grand narratives or through the intimate and interactive process of skilful storytelling. The focus of the embedded narrative on the character of Richard III is central to the children's understanding of the motivations of a power-seeker. This prompts both child characters and reader to consider the societal influences on power-seekers in their own centuries and invites questions concerning the limits that human beings will go to in order to carry out a perceived duty. The children 
understand from this that moral judgements are complex and cannot be based on social assumption.

Through embodied delivery and response, the probability of affect is increased and Hartnett also reveals where the storyteller exaggerates or manipulates the narrative to intensify an emotional response. When Cecily declares to May that the story of the Princes is just 'not real anymore' she signals key questions raised by the novel (p. 199). When does a story begin or cease to be real? Where is the boundary between certainty and truth, fact, and fiction? Certainly, with the gift of storytelling, the 'effects' of time and distance can be minimised by 'affect' in terms of the power of story to employ the imagination and in so doing create meaning. It is meaning which assists the subject to make sense of the world. Through the use of embedded narrative, Hartnett requires that the reader's imagination operates in multiple dimensions simultaneously, thus demonstrating her trust in the capacity of children to cope with complexity, exercise moral judgement, resilience, and creative power.

\section{References}

Anderson, Jon (2010). Understanding Cultural Geography: Places and Traces. London and New York: Routledge.

Carroll, Jane Suzanne (2011). Landscape in Children's Literature. New York and London: Routledge.

Cresswell, Tim (2004). Place: A Short Introduction. Malden, MA: Blackwell.

Edwards, Sophie Anne (2010). 'La Cloche, Northeastern Ontario: Liminal Passages'. Catherine Brace and Adeline Johns-Putra (eds) Process: Landscape and Text. Amsterdam and New York: Rodopi

Foucault, Michel (1980). Power/Knowledge: Selected Interviews and Other Writings. New York: Pantheon.

French, Marilyn (1986). Beyond Power: On Women, Men and Morals. London: Cardinal.

Hartnett, Sonya (2012). Life in Ten Houses (e-book). Melbourne : Penguin.

---. (2012). The Children of the King. New York and London: Penguin.

Hay, Simon (2011). A History of the Modern British Ghost Story. New York and Hampshire: Palgrave Macmillan.

Horwath, Jan (ed.) (2001). The Child's World: The Comprehensive Guide to Assessing Children in Need. London and Philadelphia: Jessica Kingsley. 
Hutcheon, Linda (1998). A Poetics of Postmodernism. London and New York: Routledge. Jackson, Anna, Karen Coats, and Roderick McGillis (eds) (2008). The Gothic in Children's Literature: Haunting the Borders. New York and London.

Kornberger, Horst (2008). The Power of Stories: Nurturing Children's Imagination and Consciousness. Edinburgh: Floris Books.

Manier, David and William (2010). 'A Cognitive Taxonomy of Collective Memories'. In Astrid Erll and Ansgar Nünning (eds) A Companion to Cultural Memory Studies. Berlin and New York: De Gruyter.

McCallum, Robyn (1999). Ideologies of Identity in Adolescent Fiction: The Dialogic Construction of Subjectivity. New York and London: Taylor \& Francis.

Merleau-Ponty, Merleau (2014). Phenomenology of Perception. London and New York: Routledge. (Original work published 1945).

Meteling, Arno (2010). 'Genius Loci: Memory, Media and the Neo-Gothic'. In Maria del Pilar Blanco. and Esther Peeren (eds) Popular Ghosts: The Haunted Spaces of Everyday Culture. New York and London: Continuum.

Nikolajeva, Maria (2010). Power, Voice and Subjectivity in Literature for Young Readers. Oxon and New York: Routledge.

Trites, Roberta Seelinger (2000). Disturbing the Universe: Power and Repression in Adolescent Literature. Iowa City: University of Iowa Press.

\section{Biographical Note}

Rose Miller is currently undertaking doctoral research on the novels of Sonya Hartnett, and working with Professor Jean Webb at the University of Worcester, UK. Rose is also a part-time lecturer on Worcester's BA in Creative and Professional Writing. 